\title{
Historisitas Pemikiran Hukum Imam Asy-Syafi'i
}

\author{
Rohidin
}

\begin{abstract}
Ass-Syafi', is well known as a "mejtahid" who developed the "qodim" and "jaidi" schools of thought which emerged after a long period of study in various legal centres araound the world. The result of these in-depth studies of various methods of schools of thought was an effort in synthesis. This environment he experienced made a signiticant contribution to the development of his legal thought. Not limited to this, he also felt that he should offer a method of throught that was systematic, thought the logic of fikih.
\end{abstract}

\section{Pendahuluan}

Bagi umat Islam Indonesia pada umumnya, mazhab Syafi'i telah menyatu dalam kehidupannya secara pribadi ataupun sosial. Sedemikian lekatnya, sehingga umat merasa tidak perlu lagi mengenal sumber dan proses penetapan hukum-hukum keagamaan. Akibatnya hubungan umat dengan ajaran mazhab lebih tampak sebagai ikatan emosional daripada ikatan intelektual rasional. Implikasi praktis dari sikap ahistoris terhadap doktrin hukum semacam itu, seringkali muncul kepermukaan ketika muncul gagasan baru di bidang hukum. Mereka kurang menyadari bahwa pemikiran hukum lebih banyak dikedepankan adalah dalam rangka memenuhi tuntutan historis, komunitas dan masa tertentu. Satu di antara yang menumbuhkan sikap semacam itu adalah kurangnya kajian historis sosiologis tentang hokum Islam, yang lebih sering hanya disesali belaka ketimbang merupakan pendorong dan penggugah untuk mengisi kekurangan ini.

Tulisan sederhana tentang perjalanan pemikiran hukum al-Syafi'i ini dimaksudkan untuk menelusuri jejak kesejarahan pemikirannya sebagai salah satu tokoh utama di bidangnya. Beberapa hal yang menarik pada diri al-Syafi'i untuk diungkap kembali adalah kenyataan bahwa dia tokoh yang pernah mengalami pendadaran di dua wilayah geografis dengan kultur pemikiran yang diametris, untuk kemudian berdikari di wilayah yang tidak dikenal sebagai basis kaum tradisional ataupun basis kaum rasional, yakni Mesir. Dari luasnya perjalanan dalam menggali berbagai pemikiran hukum dan perpindahannya dari satu wilayah ke wilayah lain inilah gagasan al-Syafi'i muncul sehingga dia dikenal memiliki mazhab qadim dan mazhab jadid.

Pertanyaan yang muncul kemudian adalah apa yang menarik al-Syafi'i untuk tidak tinggal di Hijaz tempat keluarganya berada atau tidak tinggal di Irak yang pada saat itu merupakan tempat yang paling menjanjikan, karena merupakan ibukota negara? Lalu 
mengapa dengan kepindahannya ini membawa konsekuensi perubahan kerangka pemikiran hukumnya? Pertanyaan inilah yang akan dicoba untuk dijawab dalam tulisan ini dengan harapan dapat menggugah kesadaran untuk memahami historisitas sebuah pemikiran di bidang hukum, sehingga kita tidak terjebak untuk menganggapnya sebagai suatu yang permanen dan kebal terhadap segala upaya perubahan.

\section{Riwayat Hidup dan Aktivitas Keilmuannya}

Al-Syafi'i adalah Muhammad bin Idris bin al-Abbas bin Syafi' bin al-Saib bin Ubaid bin Abdu Yazid bin Hasyim bin al-Mutholib bin Abdi Manaf.' Dari pihak lbu al-Syafi'i adalah cucu saudara perempuan ibu sahabat Ali bin Abi Thalib AS. Jadi ibu dan bapak al-Syafi'i adalah dari suku Quraisy. Bapak beliau berkelana dari Makkah untuk mendapatkan kelapangan penghidupan di Madinah, lalu bersama dengan ibu al-Syafi'i meninggalkan Madinah menuju ke Gaza untuk akhirnya beliau wafat di sana setelah dua tahun kelahiran al-Syafi' i. ${ }^{2}$ Dalam catatan yang lain al-Syafi'i lahir dalam keadaan yatim ${ }_{1}^{3}$ pada bulan Rajab Tahun 150 H. (767 M) di Gaza, Palestina.

Beratnya kehidupan di sana bagi seorang janda, membuat ibu al-Syafi'i tidak mampu bertahan hidup di sana. Sang ibu lalu membawanya ke Asqalan dan kemudian ke Makkah kembali dengan maksud agar alSyafi'i bisa hidup di tengah-tengah keluarga dan nenek moyangnya dengan kehidupan yang cukup. Kenyataannya kehidupannya di Makkah tidak lebih baik dari kehidupan yang kasar, tetapi dengan kesadaran akan penderitaan hidup inilah al-Syafi'i mulai mengawali aktivitas keilmuannya.

Aktivitas pendidikannya dimulai dengan studi al-Quran dalam hal tilawah, tajwid dan tafsirnya dengan guru-guru yang ada di Masjid al-Haram. Kesungguhan dan ketekunannya dalam menghafal al-Quran terlihat ketika pada usia sembilan tahun beliau telah mampu menghafal al-Quran dan beberapa hadits di luar kepala. Hafalannya terhadap banyak hadits lebih merupakan akibat dari kurangnya sarana untuk menulis pelajaran yang diterimanya. Di Masjid al-Haram inilah dia pernah berguru kepada Muslim bin Khalid ( $w$. $180 \mathrm{H}$ ), Sufyan bin 'Uyainah di bidang hadits dan figh, Isma'il bin Qasthantin dalam ilmu alQuran, juga pernah bertemu dengan al-Lais bin Sa'ad, ahli fiqh yang juga ahli dalam bidang sastra dan bahasa. Al-Lais ini adalah Mujtahid Mesir yang di kemudian hari kelak akan diikuti jejaknya oleh al-Syafi'i. ${ }^{4}$

Dalam suatu kesempatan di Masjid alHaram saat itu, al-Syafi'i mendengar al-Lais menganjurkan agar para siswanya memperdalam pengetahuan bahasa Arab, balaghahnya, dan berbagai cabang sastranya. Al-Lais juga berpesan agar mereka menghafal syair kuno dan yang sezaman dengan turunnya al-Quran, sebagai alat pokok untuk memahami bahasa al-Quran dan hadits dengan baik. ${ }^{5}$ Atas konspirasi inilah al-Syafi'i kemudian pergi ke

\footnotetext{
${ }^{1}$ Muhammad al Syati'i, Kitab al-Um (Mesir: Maktabah al-Kulliyat al-Azhariyah, 1961), I; Alif

2 Abdurrahman al Syarqawi, Aminah al Figh al-Tish'ah (Beirut: Dar 'lqra', 1981), hlm. 129.

${ }^{3}$ M. Abu Zahroh, Tarikh al- Mazahib al-Islamiyah; (Kairo: Dar al-Fkr4 al-:Arabi, t.t), hlm. 228.

${ }^{4}$ Munawar Khalil, Biografi Empat Serangkai Imam Mazhab (Jakarta: Bulan Bintang, 1955), hlm. 153.

${ }^{5}$ al-Syarqawi, Aimmah, hlm. 130.
} 
daerah pedalaman Arab guna mempelajari dan mendalami bahasa Arab yang masih bersih dari pengaruh bahasa luar. Al-Syafi'i hidup bersama suku Huzeil, suatu suku yang terkenal paling fasih berbahasa dan syairsyairnya sarat dengan ilmu bahasa. Dalam waktu kurang lebih sepuluh tahun ini al-Syafi'i bolak-balik antara desa suku Huzeil untuk belajar bahasa, sastra, olahraga dan ke Makkah untuk meminta nasehat dari ibundanya sekaligus belajar ilmu al-Quran dan al-Hadits dari guru-gurunya di Masjid alHaram.

Dalam bidang hadits, di Makkah dia belajar dan bahkan sampai menghafal kitab al-Muwatha'karya Imam Malik kepada Sufyan bin 'Uyainah. Menginjak usianya yang kedua puluh dia mendengar kebesaran nama Imam Malik penulis buku yang telah dia hafal. Dengan berbekal do'a dari ibu dan surat pengantar dari walikota Makkah berangkatlah al-Syafi'i muda ke Madinah untuk memasuki jenjang pendidikan tahap selanjutnya di bawah bimbingan langsung Imam Malik bin Anas. Di Madinah beliau ditanggung kehidupannya oleh Imam Malik sebagai seorang ulama yang kaya, dan seperti kebiasaannya yang dulu al-Syafi'i sering mengunjungi daerah pedesaan untuk mempelajari kehidupan mereka sehari-hari, sehingga disinyalir alSyafi'i tidak bisa selalu bersama Imam Malik. ${ }^{6}$ Namun demikian tugas pokoknya untuk belajar langsung kitab al-Muwatha' dari Imam Malik dapat terlaksana bahkan hanya dalam beberapa hari saja.
Masih dalam asuhan Imam Malik, alSyafi'i dengan izin dan rekomendasinya pergi ke Irak untuk yang pertama kalinya dengan tujuan mempelajari ilmu figh dari Muhammad bin Hasan dan Abu Yusuf sebagai pewaris figh Imam Hanafi yang terkenal rasional. ${ }^{7}$ Selama dua tahun al-Syafi'i di Irak, telah berhasil mendalami metode diskusi, metode instimbat hukum dan keluasan produk figh Abu Hanifah melalui kedua muridnya serta beberapa tokoh dari lrak, Baghdad, bahkan Anatolia (Asia Kecil) dan Harran. ${ }^{8}$ Al-Syafil i pulang dari perlawatannya itu ke Madinah dengan penghargaan yang tinggi kepada Imam Abu Hanifah. Di Madinah beliau kembali hidup bersama Imam Malik dengan membantu mengajarkan kitab Muwathahya. Setiap kali para pengagum fiqh Hijaz melontarkan tuduhan kepada Imam Hanafi, maka al-Syafi'ilah yang membelanya sekaligus mengajarkan kepada mereka bahwa siapapun yang berminat dalam studi figh maka tidak bisa lepas dari peran Imam Abu Hanifah. Sejak saat itu pula al-Syafi'i membuka acara diskusi dan adu argumentasi sebagai satu metode belajar baru yang belum pernah dibuka Imam Malik.

Profesinya yang baru sebagai wakil Imam Malik, yang merupakan awal dari karirnya di bidang pemikiran hukum atau pengajar kajian hukum, terasa cukup melegakan al-Syafii dari beban kehidupan juga membuatnya terkenal keseluruh penjuru dunia Islam. karena yang mengunjungi madrasah Imam Malik adalah tokoh-tokoh dari berbagai kota. Akan tetapi ini tidak berjalan lama, karena pada tahun 179

\footnotetext{
${ }^{6}$ Abu Zahroh, Tarikh, him. 231.

'Kudori Bik, Tarikh al-Tasyari (Jakarta: Maktabah Salim Nabban, tt.) hlm. 253.

${ }^{8}$ al-Syarqawi, Aimmah, hlm. 103-104.
} 
$\mathrm{H}$, Imam Malik meninggal dunia. Sepeninggal Imam Malik, al-Syafi'i kembali memikirkan keperluan hidupnya, setelah selama sembilan tahun menjadi murid Imam Malik dia tidak pernah memikirkan masalah penghidupan. Karena inilah kemudian al-Syafi'i menerima tawaran Walikota Yaman untuk diangkat menjadi sekretarisnya dalam usia 29 tahun. ${ }^{9}$

Selama iebih dari lima tahun al-Syafi'i mengabdi kepada pemerintah sebagai sekretaris Walikota Yaman, dia tetap bersikap sebagai seorang ilmuwan yang suka berdiskusi dengan siapapun sepanjang untuk mencari kebenaran dan bertambahnya ilmu pengetahuan. Di sini dia bergaul dengan berbagai tokoh dari kalangan Syi'ah dan bersahabat dengan seorang ahli figh murid Al-Lais bin Sa'ad. Dalam kapasitasnya sebagai seorang ilmuwan, al-Syafi'i tidak pernah menutup mata dari segala perilaku politik para penguasa di Yaman yang banyak diantaranya bertindak korup. Akibatnya dia sering sekali melontarkan kritik terhadap para pejabat daerah ini sehingga al-Syafi'i justru dituduh bertindak makar terhadap pemerintah dan dianggap memimpin gerakan Syi'ah yang saat itu sudah menjadi musuh pemerintah. Atas tuduhan inilah al-Syafi'i dikirim ke Baghdad menghadap Khalifah Harun al-Rasyid.

Melalui dialog langsung dengan alRasyid serta atas kesaksian dari Muhammad bin Hasan, yang saat itu menjabat Qadi pusat, al-Syafi'i akhirnya dibebaskan dari tuduhan, tetapi masih dalam pengawasan. Karena inilah al-Syafi'i oleh Khalifah al-Rasyid dititipkan kepada Muhammad bin Hasan. Kesempatan ini oleh al-Syafi'i justru dipergunakan sebagai jalan untuk kembali menekuni kitab-kitab fiqh Muhammad bin Hasan yang dia tulis dari pendapat Imam Hanafi. Selain menulis atSyafi'i juga mendiskușikannya secara langsung dengan lbn Hasan ini di samping juga dengan tokoh-tokoh lain bahkan di bidang ilmu empirik dan logika, sehingga menjadi lengkaplah pengetahuan al-Syafi'i tentang tradisi pemikiran hukum Irak, disamping menambah pengetahuan al-Syafi'i terhadap hadits yang banyak beredar di kalangan penduduk Irak tetapi tidak dikenal di kalangan masyarakat Hijaz melalui Muhammad bin Hasan. ${ }^{10}$

Setelah dengan jelas dia tunjukkan kepada al-Rasyid bahwa dia tidak terlibat dengan gerakan makar, bahkan dia berhasil menunjukkan keahliannya di hadapan alRasyid melalui dialognya dengan para ähli dari berbagai bidang yang diundang al-Rasyid ke istana, al-Rasyid justru tertarik untuk mengangkatnya sebagai qadli. Namun permintaan ini oleh al-Syafi'i ditolak dengan alasan ingin menjadi ahli figh yang benarbenar bebas dan karena penolakannya ini lalu al-Rasyid memberinya hadiah besar yang dia gunakan untuk kembali ke Makkah. Dengan hadiah ini al-Syafi'i memiliki bekal untuk memusatkan seluruh tenaga dan waktunya guna menekuni bidang ilmu sepulangnya ke Makkah.

Sejak ini al-Syafili telah menjadi seorang ahli dan membentuk majlis di Masjid al-Haram untuk berfatwa dan mengajar dengan pendirian yang teguh, wawasan yang dalam dan jiwa yang tenang dengan semakin bertambahnya ilmu dan usia. Sisa waktu

${ }^{9}$ Ahmad Jamil, Seratus Muslim Terkemuka (Jakarta : Pustaka Firdaus, 1987), hlm 89.

${ }^{10}$ Abu Zahroh, Tarikh, hlm. 236. 
mengajarnya dia gunakan secara khusus untuk berpikir, merenung dan mencari metode istimbat hukum yang tepat. Dengan bekal ilmu pengetahuannya yang luas dan dalam, selain mengajar al-Syafi'i menggunakan waktunya untuk menuangkan hasil renungannya dalam bentuk tulisan. Hasil renungannya tentang kaidah-kaidah universal untuk mengambil hukum dan prinsip penggalian hukum dia tuangkan dalam kitab al-Risalahnya."

Kalau pada masa-masa sebelumnya alSyafi'i sekedar mengajarkan hasil ijtihad Imam Abu Hanifah maka sekarang al-Syafi'i telah menjadi seorang mujtahid yang mandiri, melakukan berbagai kajian yang mendalam terhadap kedua pola berpikir kedua mazhab terdahulunya lalu mengkritik keduanya dan hasil studi kritis itu dia tulis dalam kitab tersendiri yang disebutnya Khilaf Malik dan Khilaf al--raqiyin. ${ }^{12}$ Walau jangka waktu untuk menulis dan mengulasnya kembali di Makkah cukup lama, tetapi belumlah dirasa cukup oleh al-Syafi'i. Beliau masih ingin merevisinya kembali setelah dia kemukakan ke berbagai pihak. Itulah sebabnya al-Syafi'i kembali ingin pergi ke Baghdad guna mendiskusikan hasil ijtihadnya sendiri dengan para sahabat Abu Hanifah.

Akhirnya pada tahun $198 \mathrm{H}$ al-Syafi'i berangkat ke Irak untuk ketiga kalinya. Kali ini kedatangannya bukan lagi untuk belajar, tetapi untuk melontarkan gagasan-gagasan barunya baik dalam bidang metodologi ataupun dalam bidang furu' atau detail-detail hukum hasil ijtihadnya. Namun Baghdad saat itu sudah berubah tidak seperti ketika al-Syafi'i di sana belasan tahun yang lalu. Sahabat sekaligus guru yang sangat dia kagumi, Muhammad bin Hasan kini telah tiada. Khalifah Harun alRasyid telah wafat dan digantikan putranya alAmin tetapi kemudian digantikan oleh alMakmun. Baghdad baru saja diguncang perang saudara akibat perebutan kekuasaan. Teman diskusinya yang paling akrab kini tinggal Ahmad bin Hambal sebagai muridnya. Karena alasan inilah al-Syafi'i melakukan dialog dengan para ahli yang masih tersisa di Baghdad hanya dalam waktu kurang lebih dua bulan, atau bahkan hanya satu bulan. ${ }^{13}$

Selanjutnya dia memutuskan untuk menggunakan sisa hidupnya di Mesir, tempat yang tidak jauh berbeda dengan Baghdad dalam hal kekayaan ilmu dan peradabannya dan wilayahnya yang subur membuat iklim berpikir di sana terasa lebih tenang jika dibandingkan dengan Baghdad sebagai kota metropolitan kala itu. Al-Syafi'i cukup sadar bahwa di Mesir terdapat beragam kemajuan terutama warisan peradaban kunonya yang telah mewarnai karakteristik manusia Mesir, mengajari mereka cinta keadilan dan kemerdekaan berpikir untuk mencari kebenaran. Di Mesir inilah al-Syafi'i dapat bersyair dengan bebas tanpa kesulitan tidak seperti di kalangan hadits yang membenci syair, karena lingkungan pemikirannya yang ramah.

Di Mesir al-Syafi'i banyak menemukan tradisi dan kebudayaan yang sama sekali baru baginya karena belum pernah dikenalinya baik di Makkah, Madinah, Yaman, Suria bahkan di Irak. Untuk inilah usaha yang pertama kali

\footnotetext{
${ }^{11}$ al-Syarqawi, Aimmah, hlm. 138.

${ }^{12}$ Abu Zahroh, Tarikh, him. 237.

${ }^{13}$ Munawar Khalil, Biografi, hlm. 196.
} 
dilakukan al-Syafi'i di Mesir adalah melacak sejarah pemikiran dan pandangan hidup masyarakat Mesir secara umum dan melacak jejak pemikiran hukum Imam al-Lais yang terkenal telah berhasil menjembatani jurang perbedaan antara mazhab Madinah (Hijaz) dan mazhab Irak. ${ }^{14}$ Akibat konkrit dari pelacakan terhadap tradisi pemikiran dan kondisi sosial geografis Mesir ini dalam bidang pemikiran hukumnya adalah berbagai perubahan terhadap hasil karyanya yang telah ditulis di Makkah dan lrak.

Selama enam tahun sisa hidupnya di Mesir al-Syafi'i yang telah menyandang gelar Imam Mujtahid, menghabiskan waktunya untuk mengajar di Masjid Jami' Fustat dan merevisi seluruh karyanya. Mula-mula beliau meninjau kembali kitab al-Risalah untuk yang kesekian kalinya, menyaring ushul fiqh yang dikandungnya dan menambah beberapa masalah yang dirasakan masih kurang. Selanjutnya beliau menganalisis pendapatpendapatnya yang mengikuti Imam Malik dan meneliti seluruh figh Imam Malik secara khusus dengan pertimbangan pengetahuan yang didapatnya di Irak dan Mesir. Dalam pertemuan khususnya, dia lontarkan kritiknya terhadap fiqh Imam Malik dan figh Abu Hanifah, yang menurutnya terlalu menekankan pada masalah-masalah partikular.

Setelah selesai menulis ulang seluruh karyanya al-Syafi'i kemudian mengumumkan bahwa pendapatnya yang final adalah yang tertulis di Mesir, yang dikembangkan dengan kajian ilmiah yang baru. Dan setelah melalui perjalanan panjang dalam memperjuangkan ilmu dan agama akhimya Imam al-Syafi'i pada tanggal 28 Rajab tahun $204 \mathrm{H}$ berpulang ke hadirat Allah SWT dalam usia lima puluh empat tahun.

\section{Sumbangan Pemikirannya terhadap Hukum Islam}

Dari uraian di atas, tampak bahwa alSyafi'i muncul pada titik balik sejarah yurisprudensi Islam yang membawa nafas baru dalam perkembangan teori hukum. $\mathrm{Di}$ atas diihat nama-nama pemikir hukum yang mewakili daerah-daerah yang berbeda-beda. Seperti telah disebut-sebut nama Abu Hanifah, Abu Yusuf dan Muhammad bin Hasan sebagai wakil aliran kedaerahan Irak, sementara Imam Malik bin Anas sebagai wakil kedaerahan Hijaz. Umumnya orang mengira bahwa mereka memperoleh ketenaran karena ijtihad bebas mereka yang didasarkan pada penalaran murni dalam lingkup hukum. Ini tampaknya membuat kita mempercayai bahwa para ahli hukum ini tidak dipengaruhi oleh lingkungan di mana mereka tinggal, atau oleh kecenderungan umum dari daerah mereka masing-masing. Hal ini tentu saja tidak benar, mengingat mereka dipengaruhi baik oleh praktek maupun pemikiran daerah masing-masing. Ini nyata sekali dari penalaran mereka: Di Madinah misalnya, sebelum tampilnya Malik di atas gelanggang pemikiran, kecenderungan pendapat khusus telah ada sebelumnya.

Sebelum Malik, di Madinah telah hidup sejumlah sahabat maupun tabi'in yang memiliki wawasan luas dalam ilmu hukum. Mereka umumnya dikenal dengan tujuh ahli

${ }^{14}$ al-Syarqawi, Aimmah, hlm. 123. 
figh dari Madinah, yang telah banyak menyumbangkan pemikiran terhadap pembentukan pendapat hukum di Madinah. Para pendahulu Malik ini meninggalkan warisan pendapat hukum yang melimpah di samping tradisi yang melekat dalam masyarakat yang mengakibatkan terkendalinya perkembangan pemikiran sehingga Malik merasa tidak terlalu perlu melakukan ijtihad dengan mengandalkan rasio. Inilah mengapa kemudian alirannya begitu mengamalkan praktek yang hidup di lingkungan Madinah saja.

Kondisi serupa juga terjadi di Irak. Suatu kecenderungan pendapat di Irak sudah terbentuk sebelum tampilnya Abu Hanifah. Tokoh-tokoh seperti Ibnu Mas'ud, Ibrahim alNakha'i, al-Sya'bi dan lain-lain adalah orangorang yang banyak meninggalkan warisan keputusan hukum. Hanya saja karena sebagai kota metropolitan kala itu, Irak memiliki problematika yang lebih komplek sesuai dengan mobilisasi dan interaksi sosial masyarakat yang telah maju, sementara tradisi awal sebelum masuknya Islam di sana tidak banyak yang perlu dipertahankan sebagai sunnah, maka mereka banyak mengandalkan rasio yang diaplikasikannya dalam Qiyas dan Istihsan.

Sementara proses kristalisasi pendapat hukum dalam berbagai mazhab berjalan, alSyafi'i tampil ke permukaan. la mempelajari karya-karya pendahulunya, berkelana ke berbagai wilayah, melakukan diskusi panjang dengan para ahli hukum Madinah dan Irak dan akhirnya mengambil jalan mengkompromikan kedua kecenderungan yang telah ada sebelumnya. Kemudian al-Syafi'i mengembangkan teori hukumnya sendiri dan mencoba untuk konsisten dengan metodologi istimbat hukum yang dia gariskan dalam alRisalahnya. Karena langkah inilah maka kemudian al-Syafi'i dikenal sebagai pembaharu abad kedua Hijriyah. ${ }^{15}$

Di antara konsep pembaharuan al-Syafi'i, yang lebih merupakan upaya merujukkan kedua aliran yang mendahuluinya, adalah rumusan tentang sistematika sumber hukum setelah al-Quran. Yakni :

1. al-Sunnah

Berbeda dengan pandangan kaum rasionalis ekstrim yang menolak sunnah sebagai sumber hukum, tetapi juga berbeda dengan konsep sunnah mazhab Malik yang terlalu longgar, al-Syafi'i menawarkan konsep sunnah yang betulbetul otentik dari Nabi. ${ }^{16}$

2. ljma'

Urutan ketiga sumber hukum yang dikemukakan al-Syafi'i adalah ijma' umat. Dia menolak konsep ijma'nya Imam Malik yang hanya terbatas pada kesepakatan Ulama. Menurutnya umat tak mungkin bersepakat dalam kesalahan. ${ }^{17}$

\section{Qiyas}

Berbeda dengan kaum rasionalis yang menempatkan qiyas dalam urutan di atas ijma' atau bahkan hadits ahad, juga berbeda dengan ahli hadits yang menolak penggunaan qiyas, maka al-Syafi'i

${ }^{15}$ DB. McDonald, Development of Muslim Theology, Jurisprudence and Constitutional Theory, (New York, ttp. , 1903), hlm. 104.

${ }^{16}$ al-Syafi'i, al-Um, hlm. VII: 179, 274.

${ }^{17}$ al-Syafi'i, al-Risalah, terj. Anmadie Toha (Jakarta : Pustaka Firdaus, 1986), hlm. 66. 
berpendapat bahwa qiyas dapat digunakan dalam kondisi tidak ditemukannya ijma' atau nash. Konsep ini sesungguhnya dikemukakan untuk menolak penggunaan ra'yu yang tak terbatas yang menurutnya bersifat arbiter dan subyektif. ${ }^{18}$

Sedangkan ilustrasi-ilustrasi tentang perubahan produk ijtihad beliau dalam masalah partikular, yang disebabkan oleh kondisi sosio historis yang berbeda di antaranya dapat ditemukan dalam ijtihadnya mengenai tanah dan air. Imam Syafi'i semula sependapat dengan Imam Malik bahwa pemilik tanah yang ada sumurnya boleh menjual sumur itu. Untuk kondisi daerah yang air terlalu berharga karena langkanya seperti di daerah hijaz tentu saja pendapat ini bisa dibenarkan. Akan tetapi di daerah sungai Nil yang subur dan air tidak terlalu merisaukan, maka pendapatnya di atas kurang tepat. Itulah sebabnya buru-buru ia merubah pendapatnya dengan menyatakan bahwa pemilik tanah itu tak berhak menjual sumurnya, tetapi dia mendapat prioritas untuk menggunakan airnya. ${ }^{19}$

Demikian halnya dalam masalah saksi, di mana ketika di Irak al-Syafi'i berpendapat bahwa satu orang laki-laki cukup untuk saksi ditambah dengan sumpah. Tetapi ketika di Mesir pendapat ini kemudian dirubahnya dan kembali pada pendapat bahwa saksi harus dua orang laki-laki. ${ }^{20}$ Jika dilacak secara sosio historis, pendapat yang pertama diajukan lebih disebabkan oleh kondisi masyarakat lrak yang individualistis sebagai cerminan masyarakat kota, sedangkan ketika di Mesir kondisi serupa itu tidak lagi menonjol sesuai dengan karakteristik masyarakat Mesir yang kaya dengan peradaban dan cinta keadilan.

\section{Simpulan}

Dari uraian di atas, menjadi jelaslah historisitas pemikiran hukum seorang mujtahid. Al-Syaff'i yang muncul sebagai seorang mujtahid ketika di dunia Islam telah mengenal dikotomi hadits-ra'yu atau tradisional-rasional yang dalam banyak hal seringkali menimbulkan pertentangan yang tidak logis. Oleh karena kemunculan al-Syafi'i setelah melewati masa pengembaraannya yang lama di pusat-pusat studi hukum, dengan hasil perolehan pengetahuan yang mendalam tentang aliran pemikiran yang berkembang lebih merupakan upaya sintesis. Suasana yang dilaluinya ini memberikan sedikit andil yang cukup besar dalam membentuk perkembangan pemikirannya. Itulah sebabnya, al-Syafi' iterkenal sebagai mujtahid yang memiliki mazhab qadim dan mazhab jadid. Lebih dari itu mengingat dalam mazhab-mazhab sebelumnya, sehingga dia merasa perlu menawarkan metode berpikir yang sistematis yakni melalui ushul figh.

Kepindahannya dari Hijaz ke Irak adalah dalam rangka usahanya menawarkan gagasan barunya yang bersifat sintesis, karena pertentangan ra'yu versus hadits, di Irak relatif lebih menonjol. Akan tetapi ternyata di Irak sedang terjadi pergolakan pemikiran terutama pemaksaan teologi Mu'tazilah oleh pemerintah

${ }^{19}$ A. Hassan, The Early Development of Islamic Jurisprudence (Islamabad: Islamic Research institute, 1970), him. 51.

${ }^{19}$ al-Syarqawi, Aimmah, hlm. 130

${ }^{20} \mathrm{lbid}, \mathrm{hlm} .132$. 
al-Makmun sehingga al-Syafi'i memilih menghindar dari konflik yang bakal ditimbulkan oleh upaya ini. Alasan lain kepindahan al-Syafi'i dari Irak ke Mesir adalah juga upaya al-Syafi'i al-Makmun mengangkat dominasi Persia atas Arab, sehingga al-Syafii sebagai seorang Arab merasa terpojok di Irak, sedang Mesir masih tetap dipimpin oleh wali yang berbangsa Arab yakni Abbas bin Musa.

Perbedaan lingkungan geografis dan kultural antara Irak dan Mesir, ternyata membawa dampak perubahan beberapa produk pemikirannya yang telah lalu. $\mathrm{Hal}$ ini dilakukannya tidak saja karena di Mesir sudah pernah berkembang pemikiran hukum al-Lais, tetapi karena keinginannya untuk menawarkan gagasan hukum yang historis dan sesuai dengan tuntutan sosialnya. Demikianlah sedikit yang dapat disimpulkan dari perjalanan. pemikiran hukum al-Syafi'i.

\section{Daftar Pustaka}

Abu Zahroh, Tarikh al-Mazahib al-Islamiyah,
Kairo, Dar al-Fikr al-Arabi, tt.

Bik, Khudori, Tarikh al-Tasyri' al-Islami, Jakarta, Maktabah Salim Nabhan, tt.

Hasan A., The Early Development of Islamic .Jurisprudence, Islamabad, Islamic Research Institute, 1970.

Jamil, Ahmad, Seratus Muslim Terkemuka, Jakarta, Pustaka Firdaus, 1987.

Khalil Munawar, Biografi Empat Serangkai Imam Mazhab, Jakarta, Bulan Bintang, 1955.

McDonald, DB. Development of Muslim Theology, Jurisprudence and Constitutional Theory, New York, Tnp., 1903.

Al-Syafi'i, Muhammad Ibn Idris, al-Um, Mesir, Maktabah al-Kulliyat al-Ashariyah, 1961.

, al-Risalah, terj. A. Thaha, Jakarta, Pustaka Firdaus, 1986.

Al-Syarqawi, Abdurrahman, A'immah al-Figh al-Tis'ah, Beirut, Dar al-lqra', 1981. 